\title{
Visual response effects of western flower thrips manipulated by different light spectra
}

\author{
Qihang Liu ${ }^{1,2 \#}$, Yueli Jiang ${ }^{1 \#}$, Jin Miao ${ }^{1}$, Zhongjun Gong ${ }^{1}$, Tong Li ${ }^{1}$, Yun Duan ${ }^{1}$, Yuqing Wu ${ }^{1 *}$ \\ (1. Institute of Plant Protection, Henan Academy of Agricultural Sciences, Zhengzhou 450002, China; \\ 2. Henan Institute of Science and Technology, Xinxiang 453003, China)
}

\begin{abstract}
To understand how spectral light wavelength affects thrips visual sensitivity, the selective response and the approach sensitivity of western flower thrips were examined. The results showed that light intensity affected thrips selective sensitivity to different spectra, with good visual sensitivity to blue, ultraviolet (UV), and green light changes to UV, violet, and yellow light when illumination increased from 120 lx to $6000 \mathrm{~lx}$. Red light was the sensitive spectral light driving thrips to respond to sensitive light. Under illumination, the best sensitivity response to spectra was violet, while under light energy, this changed to UV when light energy was increased to $120 \mathrm{~mW} / \mathrm{cm}^{2}$. However, the photo-stimulus properties (illumination or light energy) did not affect the optimal approach sensitivity to UV light. Furthermore, when illumination or light energy stimulated thrips to select two different spectral lights, the total response sensitivity to $12000 \mathrm{~lx}$ of UV and violet light were the best (83.27\%), while at $60 \mathrm{~mW} / \mathrm{cm}^{2}$ of UV and yellow light was the best (82.15\%). But different photo-stimulus properties influenced on the total approach sensitivity to the stimulation of two different spectral lights when the intensity of light increased, showing that to $12000 \mathrm{~lx}$ of violet and green light was the best (53.18\%), while for $120 \mathrm{~mW} / \mathrm{cm}^{2}$ of UV and green light was the best (47.74\%). The thrips visual selection response effects stimulated by illumination were different from that induced by light energy, and originated from the thrips different bio-regulatory effects caused by the intensity of light energy of illumination and the intensity of illumination of light energy. Therefore, different photo-stimulus effects can manipulate thrips visual sensitivity to enhance the phototactic effect.
\end{abstract}

Keywords: western flower thrips, visual response effect, spectral light, illumination, light energy

DOI: $10.25165 /$ j.ijabe.20191205.4922

Citation: Liu Q H, Jiang Y L, Miao J, Gong Z J, Li T, Duan Y, et al. Visual response effects of western flower thrips manipulated by different light spectra. Int J Agric \& Biol Eng, 2019; 12(5): 21-27.

\section{Introduction}

Western flower thrips, Frankliniella occidentalis (Thysanoptera), is a serious worldwide pest found on vegetables, flowers, and other crops, but it has also spread rapidly in recent years, becoming seriously harmful as a main alien invasive pest in China ${ }^{[1]}$. Its individual size is small, the activity is often concealed, chemical pesticides have no efficacy when sprayed on thrips, and this can easily result in insecticide resistance ${ }^{[2]}$. At present, by using insect positive and negative affinity to specific light waves, color-light induction technology has become a green agricultural way to control thrips pests ${ }^{[3,4]}$. Therefore, a study of the visual selection response characteristics of thrips induced by

\section{Received date: 2019-01-17 Accepted date: 2019-07-30}

Biography: Qihang Liu, PhD, Lecturer, research interests: insects capturing technology of optical-mechanical-electrical integration, Email: bjliuqihang@ 163.com; Yueli Jiang, PhD, Assistant Researcher, research interests: agricultural insects and pest control, Email: yueli006@126.com; Jin Miao, PhD, Associate Professor, research interests: insect behavior and insect ecology, Email: miaojin1977@163.com; Zhongjun Gong, PhD, Associate Professor, research interests: insect behavior and insect ecology, Email: gongzj2@hotmail.com; Tong Li, PhD, Associate Professor, research interests: agricultural insects and pest control, Email: tongli84@hotmail.com; Yun Duan, PhD, Associate professor, research interests: Agricultural insects and pest control, Email: duanyunhao@163.com. \#Both authors contributed equally to this work and are co-first authors.

*Corresponding author: Yuqing Wu, PhD, Professor, research interests: insect behavior and insect ecology. Mailing address: Natural Enemy Laboratory, Institute of Plant Protection, Henan Academy of Agricultural Sciences, Zhengzhou, China. Tel: +86-371-65738134, Email: yuqingwu36@hotmail.com. light may reveal the sensitive light characteristics of thrips phototactic responses, thereby providing a theoretical investigation of thrips phototactic mechanisms and the photosensitization changes of thrips biological effects induced by light.

Previous researchers have studied sticky traps for thrips pests utilizing insect color discrimination. Moffitt et al. ${ }^{[5]}$ reported that yellow, blue, or white sticky traps were currently recommended for monitoring and controlling thrips. It is also reported that varying color combinations could be more attractive to thrips. For example, a yellow trap on a black, violet, or blue background may catch greater numbers of $F$. occidentalis, but this is affected by the size and shape of the traps ${ }^{[6]}$. This may be because the colors simulate the natural background conditions with a suitable wavelength and a suitable color intensity ${ }^{[7-9]}$. Thus, a study of the selection mechanism of thrips color perception behavior could help to predict what could manipulate the thrips visual behavior response. Matteson et al. studied the phototactic behavior of $F$. occidentalis using a retinal potential technique to show the peak value at $540 \mathrm{~nm}$, further speculating that the photoreceptor types of thrips adults may detect green light, blue light and ultraviolet light ${ }^{[10-12]}$. Fan et al. found that the light spectrum had a great impact on thrips phototactic behavior; the influencing effects of light intensity was greater than the wavelength ${ }^{[13-15]}$, indicating that thrips compound eyes had a strong self-regulation and adaptation mechanism to light intensity, and could select different spectral light wavelengths. Murata et al. found that the visual sensitivity of Thrips palmi ranged from UV to red light ${ }^{[16]}$. However they did not determine which wavelength was a more sensitive spectral light for thrips visual selection, and did not 
determine a mechanism for why spectral light affected the generation of thrips visual responses and changes of thrips visual response behaviors.

To explore the visual selection mechanism of $F$. occidentalis for different light spectra, and the resulting effects on thrips biological behavior manipulated by light, the effects of different light spectra on the visual selection behavior of $F$. occidentalis adults were investigated for different behavior responses in the laboratory. We also analyzed the influence of light factors on thrips phototactic responses to explain the cause of thrips visual responses and to identify the optimal trap light for controlling thrips.

\section{Materials and methods}

\subsection{Insects}

Western flower thrips samples were obtained from flowers of different plants in the Zhengzhou area of Henan Province, China, and were used to establish a laboratory colony. The insects were reared on green bean pods (Phaseolus vulgaris L.) in rearing cages, at $(25 \pm 1)^{\circ} \mathrm{C}$ with $70 \% \pm 5 \%$ relative humidity under a light/dark cycle of $14 \mathrm{~h}: 10 \mathrm{~h}$ photoperiod, respectively. Thirty thrips adults per group were kept $30 \mathrm{~min}$ in plastic containers $(40 \mathrm{~mm} \times 50 \mathrm{~mm})$ before the experiments.

\subsection{Light radiation and light measurements}

The spectra of $3 \mathrm{~W}$ LED with peak wavelengths used in the experiments were: red $(660 \mathrm{~nm})$, orange $(610 \mathrm{~nm})$, yellow $(560 \mathrm{~nm})$, green $(520 \mathrm{~nm})$, blue $(465 \mathrm{~nm})$, violet $(405 \mathrm{~nm})$, UV (365 nm), and white (composite wavelength). The incident illumination calibrated by an illuminance meter (Model: TES-1335, Resolving power: $0.01 \mathrm{l} \times$ ) was set to $6000 \mathrm{~lx}$, and $12000 \mathrm{~lx}$, respectively, and the radiating energy calibrated by a radiation meter (Model: FZ-A, resolving power: $\pm 5 \%$ ) was set to $60 \mathrm{~mW} / \mathrm{cm}^{2}$, and $120 \mathrm{~mW} / \mathrm{cm}^{2}$, respectively, to minimize the influencing effects of illumination and light energy on thrips visual selection response.

\subsection{Experiment 1 (Thrips visual selection response induced by different light spectra)}

To screen the thrips light sensitive spectra, we used device 1 (Figure 1) to test the thrips visual selection response.

The device used eight channels (length $\times$ width $\times$ height: $150 \mathrm{~mm} \times 30 \mathrm{~mm} \times 60 \mathrm{~mm}$ ) and a circular reaction chamber $(\Phi 100 \mathrm{~mm} \times 80 \mathrm{~mm})$, placed on a circular platform. Each channel was connected to the reaction chamber and was separated by a gate. Channels 1-8 were divided into three sections, marked with $0 \mathrm{~mm}$, $50 \mathrm{~mm}, 100 \mathrm{~mm}$, and $150 \mathrm{~mm}$ to identify thrips visual selection responses. The LED with the spectrum of red, orange, yellow, green, blue, violet, UV, and white were placed at the front end of channels 1-8.

Thrips visual selection response effects were measured by using device 1 at $(25 \pm 1)^{\circ} \mathrm{C}$ in darkness. Before the experiment, incident light was set to the same illumination of $6000 \mathrm{~lx}$ and
$12000 \mathrm{~lx}$, respectively, and the same radiating energy of 60 and $120 \mathrm{~mW} / \mathrm{cm}^{2}$, respectively. Corresponding to every illumination or energy, three groups of thrips received 30 min dark adaptation prior to experimentation. When testing, a group of thrips was introduced into the reaction chamber, and the gates were opened and LEDs turned on for $10 \mathrm{~min}$. After that, the gates were closed and LEDs turned off, then the lamp in the laboratory was turned on to count and record thrips present in channels 1-8; the three groups were tested individually until the experiment was completed. Using the same method, the thrips visual selection response caused by every light mode was determined.

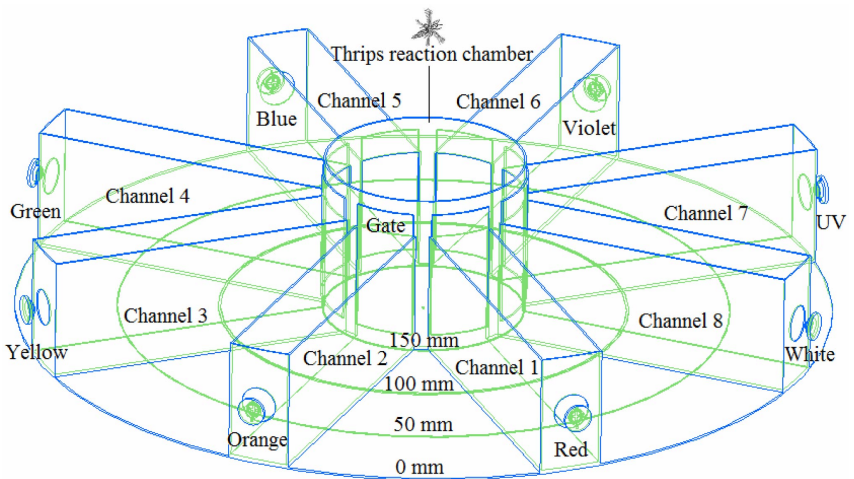

Figure 1 Device used in experiment 1 to investigate thrips visual selection response induced by different light spectra

\subsection{Experiment 2 (The contrast selection effects of thrips responding to two different light spectra)}

Based on the results from Experiment 1, LED light spectra were divided into classes: red, orange, white light, and yellow, green, violet, and UV light. Experimental device 2 (Figure 2) was used to investigate thrips sensitive selection effects of two different light spectra. The device had two channels (length $\times$ width $\times$ height: $150 \mathrm{~mm} \times 30 \mathrm{~mm} \times 60 \mathrm{~mm}$ ) and a circular reaction chamber $(\Phi 100 \mathrm{~mm} \times 80 \mathrm{~mm})$. A gate between them was used to avoid light interference. Section divisions of channels were marked with $0 \mathrm{~mm}, 50 \mathrm{~mm}, 100 \mathrm{~mm}$, and $150 \mathrm{~mm}$ to analyze the thrips visual response effects. The two LEDs were placed at the front end of the two channels. The measured spectra vs. contrast spectra were red vs. orange, red vs. white, orange vs. white, yellow vs. green, yellow vs. violet, yellow vs. UV, green vs. violet, green vs. UV, and violet vs. UV.

The LED spectrum vs. contrast LED spectrum determination was done at the same illumination $(6000 \mathrm{~lx}, 12000 \mathrm{~lx})$ or light energy $\left(60 \mathrm{~mW} / \mathrm{cm}^{2}, 120 \mathrm{~mW} / \mathrm{cm}^{2}\right)$, and three groups of thrips, after 30 min dark adaptation, were used to test the thrips contrast selection at $(25 \pm 1)^{\circ} \mathrm{C}$ in darkness. When testing, a group was introduced into the bottom reaction chamber, using the same method as in Experiment 1. The three groups were each analyzed individually. After every investigation, the thrips distributed in the two channels were counted and recorded.

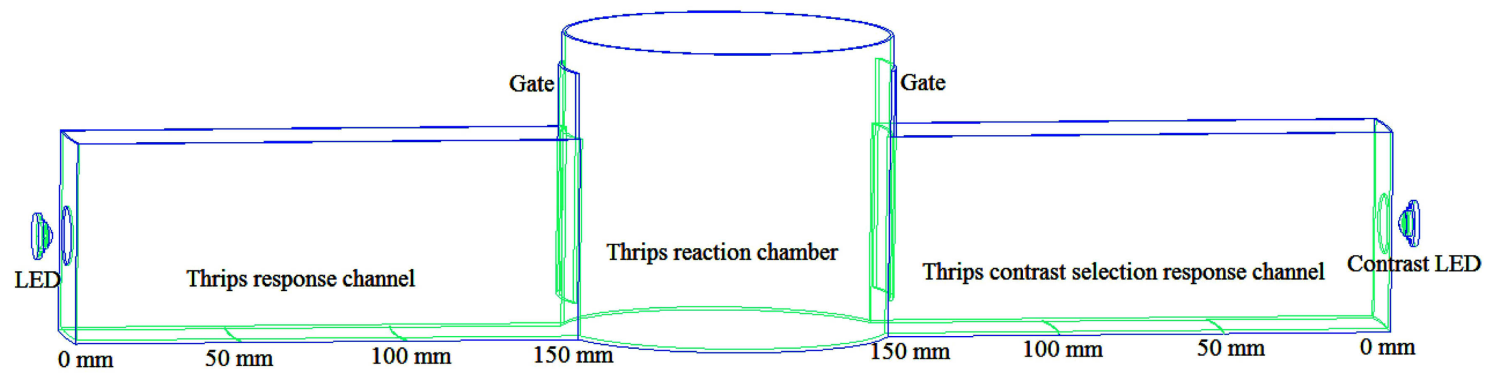

Figure 2 The device used in Experiment 2 to investigate thrips sensitive selection effects for two different light spectra 


\subsection{Data computation and analysis}

The thrips numbers of every group were recorded at $0-50 \mathrm{~mm}$ and $0-150 \mathrm{~mm}$ in every channel. We calculated the percentage of the recorded thrips numbers for 30 thrips. Then the mean percentage of the three groups was calculated to analyze the thrips visual selection response effect (thrips selective sensitivity, thrips selective approach sensitivity). In Experiments 1 and 2, the selective response rate (the mean percentage at $0-150 \mathrm{~mm}, \%$ ) was used to reflect thrips selective sensitivity (thrips selective response degree) to every light spectra. To reflect thrips approach sensitivity (intensity, Experiment 1), and the approach rate (\%) was used to compare the percentage of the mean percentage at 0-50 $\mathrm{mm}$ with that at $0-150 \mathrm{~mm}$. The data from Experiment 2 directly reflected the mean percentage at $0-50 \mathrm{~mm}$. In Experiment 2, the contrast approach rate (\%), and the contrast response rate (\%) were the mean percentage at one channel section $(0-50 \mathrm{~mm}, 0-150 \mathrm{~mm})$ subtracted from that at the same section of the other channel, and were separately calculated, reflecting the difference of thrips contrast selection effect between two spectral lights. The total approach rate and the total response rate was the sum of the mean percentages at $0-50 \mathrm{~mm}$ or $0-150 \mathrm{~mm}$ in all channels, respectively, reflecting the thrips total approach sensitivity, and thrips total response sensitivity (thrips total response degree).

General linear model analysis was employed to compare the mean percentage of insects induced by each LED, and for multiple comparisons: LSD, LSD tests at $p=0.025$ were used. The Student's $t$-test was used to determine the difference between two different light intensities with the same spectrum in Experiments 1 and $2(p=0.025)$, and between two different spectrum with the same light intensity in Experiment $2(p=0.025)$. SPSS, version 16.0 (SPSS Inc., Chicago, IL, USA) and Excel Software for windows were used for all statistical analyses. Results are shown as the mean \pm standard error (SE).

\section{Results and discussion}

\subsection{Thrips visual selection response effect induced by different light spectra}

Thrips selective responses to every light spectra tested are shown in Table 1.

On the same horizontal line, the same small letter shows no significant difference $(p>0.025)$, different letters with the same single superscript show significant differences $(p<0.025)$, and the others show extremely significant differences $(p<0.0001)$ with unmarked superscripts. Between $6000 \mathrm{~lx}$ and $12000 \mathrm{~lx}$, or $60 \mathrm{~mW} / \mathrm{cm}^{2}$ and $\mathrm{mW} / \mathrm{cm}^{2}$, AA shows no significant difference $(p>0.025) ; \mathrm{A}^{*} \mathrm{~B} *$ shows very significant differences $(p<0.025)$ on the same vertical row.

The selective response rate differed significantly under the same intensity of light $(6000 \mathrm{~lx}: F=40.75$, df $=7, p<0.0001$; $12000 \mathrm{~lx}: F=73.487, \mathrm{df}=7, p<0.0001 ; 60 \mathrm{~mW} / \mathrm{cm}^{2}: F=65.635, \mathrm{df}=7$, $p<0.0001 ; 120 \mathrm{~mW} / \mathrm{cm}^{2}: F=15.878, \mathrm{df}=7, p<0.0001$ ) (Table 1). The thrips selective sensitivities to red, orange, and white light were the worst, while sensitivities to yellow, green, violet, and UV light were better. Therefore, thrips selective sensitivity was decided by the light spectrum.

Table 1 Selective response rate of thrips induced by spectral light illumination and energy at 0-150 $\mathrm{mm} / \%$

\begin{tabular}{|c|c|c|c|c|c|c|c|c|c|}
\hline \multicolumn{2}{|c|}{ Spectrum } & red & orange & yellow & green & blue & violet & U.V. & white \\
\hline \multirow{2}{*}{$\begin{array}{l}\text { Illumination } \\
/ / \mathrm{x}\end{array}$} & 6000 & $1.11 \pm 1.11 \mathrm{a}^{*} \mathrm{~A}$ & $4.44 \pm 1.27 \mathrm{a}^{\triangle} \mathrm{A}$ & $16.65 \pm 1.92 \mathrm{~b}^{\# \star} \mathrm{g} \mathrm{A}$ & $12.21 \pm 1.11 \mathrm{c}^{\#} \mathrm{hiA}$ & $9.99 \pm 1.11 \mathrm{~d}^{* \triangle} \mathrm{hjA}$ & $22.20 \pm 1.11 \mathrm{e}^{\star} \mathrm{A}^{*}$ & $14.44 \pm 1.1$ fgij $\mathrm{A}$ & $1.11 \pm 1.11 \mathrm{aA}$ \\
\hline & 12000 & $2.22 \pm 1.11 \mathrm{aA}$ & $4.60 \pm 1.11 \mathrm{aA}$ & $21.09 \pm 1.11 \mathrm{bA}$ & $15.54 \pm 1.11 \mathrm{cA}$ & $8.88 \pm 0.00 \mathrm{~d}^{* \triangle} \mathrm{A}$ & $14.44 \pm 1.11 \mathrm{c}^{*} \mathrm{~B}^{*}$ & $15.54 \pm 0.54 \mathrm{c}^{\triangleleft} \mathrm{A}$ & $2.22 \pm 1.11 \mathrm{aA}$ \\
\hline \multirow{2}{*}{$\begin{array}{l}\text { Light energy } \\
/ \mathrm{mW} \cdot \mathrm{cm}^{-2}\end{array}$} & 60 & $1.11 \pm 1.11 \mathrm{aA}$ & $3.33 \pm 1.11 \mathrm{aA}$ & $19.98 \pm 1.92 \mathrm{~b}^{* \triangle} \mathrm{A}$ & $9.99 \pm 0.00 \mathrm{c}^{\# *} \mathrm{~A}$ & $7.78 \pm 1.11 \mathrm{cdA}$ & $25.46 \pm 1.08 \mathrm{e} * \mathrm{~A}$ & $15.54 \pm 1.11 \mathrm{f}^{\triangle \#} \mathrm{~A}$ & $4.44 \pm 1.11 \mathrm{a}^{*} \mathrm{dA}$ \\
\hline & 120 & $2.22 \pm 1.11 \mathrm{a}^{*} \mathrm{~A}$ & $2.22 \pm 1.11 \mathrm{a} * \mathrm{~A}$ & $16.67 \pm 1.92 \mathrm{bcA}$ & $12.21 \pm 1.11 \mathrm{~b}^{* \Delta \#} \mathrm{~A}$ & $6.67 \pm 1.92 \mathrm{a}^{\triangle} \mathrm{A}$ & $19.99 \pm 1.92 \mathrm{c}^{\#} \mathrm{~A}$ & $14.43 \pm 1.12 \mathrm{bcA}$ & $3.33 \pm 2.22 \mathrm{aA}$ \\
\hline
\end{tabular}

Table 2 Approach rate of western flower thrips selecting yellow, green, violet, and U.V. light /\%

\begin{tabular}{cccccc}
\hline Spectrum & \multicolumn{1}{c}{ yellow } & green & violet & UV \\
\hline \multirow{2}{*}{ Illuminatio/lx } & 6000 & $17.45 \pm 0.74 \mathrm{a}^{*} \mathrm{~A}$ & $0.00 \pm 0.00 \mathrm{bA}$ & $44.8 \pm 2.26 \mathrm{c}^{\Delta} \mathrm{A}$ & $31.50 \pm 3.36 \mathrm{~d}^{* \Delta} \mathrm{A}$ \\
& 12000 & $14.85 \pm 0.96 \mathrm{a}^{* *} \mathrm{~A}$ & $0.00 \pm 0.00 \mathrm{~b}^{* *} \mathrm{~A}$ & $52.32 \pm 2.16 \mathrm{c}^{\Delta} \mathrm{A}$ & $35.52 \pm 3.78 \mathrm{~d}^{\Delta} \mathrm{A}$ \\
\hline \multirow{2}{*}{ Light energy $/ \mathrm{mW} \cdot \mathrm{cm}^{-2}$} & 60 & $0.00 \pm 0.00 \mathrm{a}^{* *} \mathrm{~A}$ & $0.00 \pm 0.00 \mathrm{a}^{* *} \mathrm{~A}$ & $52.65 \pm 0.99 \mathrm{~b}^{* *} \mathrm{~A}^{* *}$ & $61.65 \pm 1.37 \mathrm{c}^{* *} \mathrm{~A}^{* *}$ \\
& 120 & $0.00 \pm 0.00 \mathrm{a}^{* *} \mathrm{~A}$ & $0.00 \pm 0.00 \mathrm{a}^{* *} \mathrm{~A}$ & $23.72 \pm 0.64 \mathrm{~b}^{* *} \mathrm{~B}^{* *}$ & $33.28 \pm 1.46 \mathrm{c}^{* *} \mathrm{~B}^{* *}$ \\
\hline
\end{tabular}

On the same horizontal line, the same small letter shows no significant difference $(p>0.025)$, different letters with the same single superscript show very significant differences $(p<0.025)$, and the other different letters show extremely significant differences $(p<0.0001)$ for the same illumination. For the same light energy, ${ }^{* *}$ show extremely significant differences $(p<0.0001)$. Between $6000 \mathrm{~lx}$ and $12000 \mathrm{~lx}$, or $60 \mathrm{~mW} / \mathrm{cm}^{2}$ and $120 \mathrm{~mW} / \mathrm{cm}^{2}$, AA shows no significant difference $(p>0.025)$, and $\mathrm{A}^{* *} \mathrm{~B}^{* *}$ show extremely significant differences $(p<0.025)$ on the same vertical row.

Because thrips showed no approach sensitivity to red, orange, blue, and white light, we only calculated the approach rates of thrips for yellow, green, violet, and UV light (Table 2). Thrips approach sensitivity to yellow, green, violet, and UV light showed extremely significant differences $(\mathrm{df}=3, p<0.0001,6000 \mathrm{~lx}$ : $F=86.90 ; 12000$ lx: $F=106.25 ; 60 \mathrm{~mW} / \mathrm{cm}^{2}: F=321.43 ; 120 \mathrm{~mW} / \mathrm{cm}^{2}$ : $F=452.43$ ). Under illumination, thrips approach sensitivity to violet light was the greatest. Under various tested light energies, thrips approach sensitivity to UV light was the greatest. These results indicated that the increasing illumination of thrips approach sensitivity to violet and UV light were enhanced, while that to yellow light was less. However, with increasing light energy, thrips approach sensitivity to violet and UV light was less. Therefore, photo-stimulus properties affect thrips approach sensitivity to spectral light.

\subsection{Thrips contrast selection to two different light spectra}

3.2.1 The contrast selection effect among different pairings of white, red, and orange light

Thrips total response degree showed no significant difference among different pairings $(\mathrm{df}=2,6000 \mathrm{~lx}: F=1.657, p=0.267$; $12000 \mathrm{~lx}: F=1.482, p=0.300 ; 60 \mathrm{~mW} / \mathrm{cm}^{2}: \quad F=0.439, p=0.664$; $120 \mathrm{~mW} / \mathrm{cm}^{2}: F=0.281, p=0.764$ ) (Figure $3 \mathrm{a}$ ), while the total response rate was enhanced by approximately 5\% when light intensity increased.

Thrips selective sensitivity to white light was the optimal, followed by orange light, red light (Figure 3b). Between $6000 \mathrm{~lx}$ and $12000 \mathrm{~lx}$, the contrast response rate in white vs. red light ( $F=27.05, p=0.007)$, and white vs. orange light $(F=12.50, p=0.024)$ showed significant differences, while it increased to $25.51 \%$ in 
white vs. red light, and to $32.20 \%$ in white vs. orange light, then decreased to $41.36 \%$ in orange vs. red light, when light energy increased from 60 to $120 \mathrm{~mW} / \mathrm{cm}^{2}$. These results indicated that the worst sensitivity spectrum was red, followed by orange.

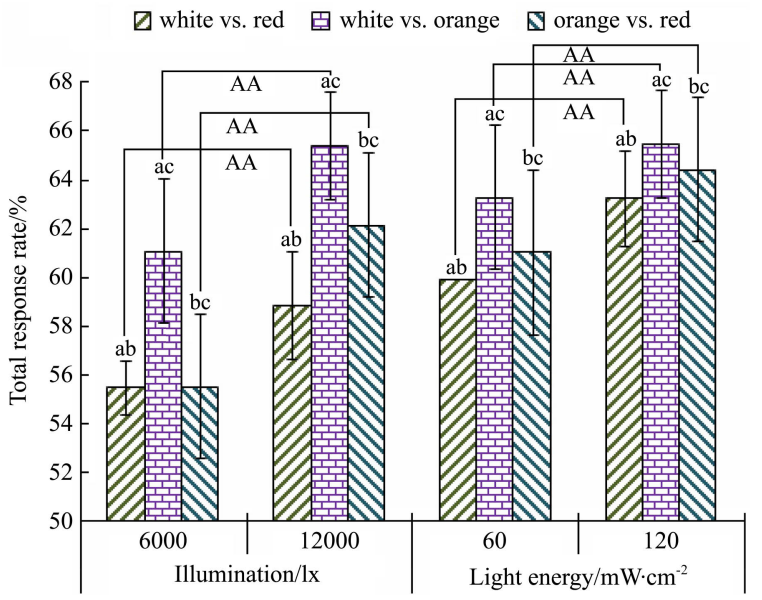

a. Total response rate at $0-150 \mathrm{~mm}$

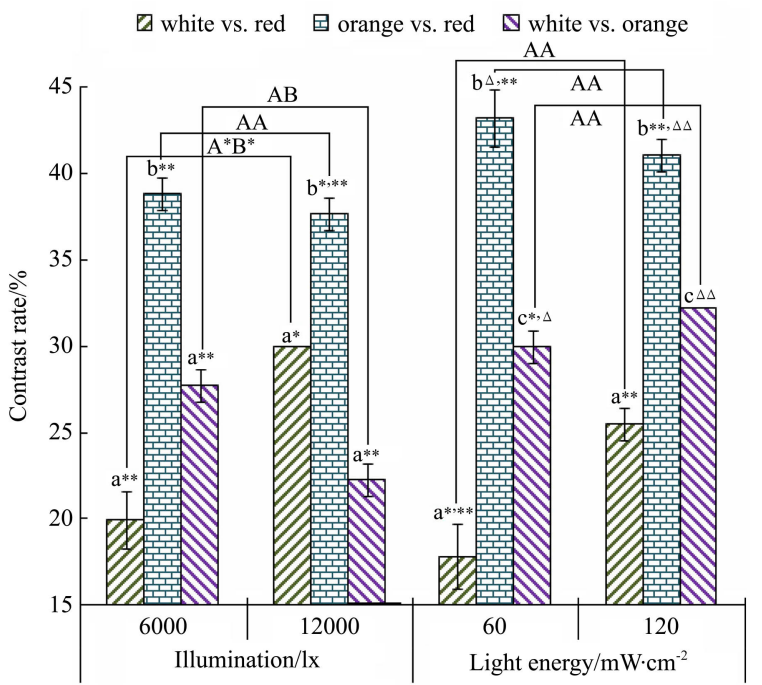

b. Contrast response rate at $0-150 \mathrm{~mm}$

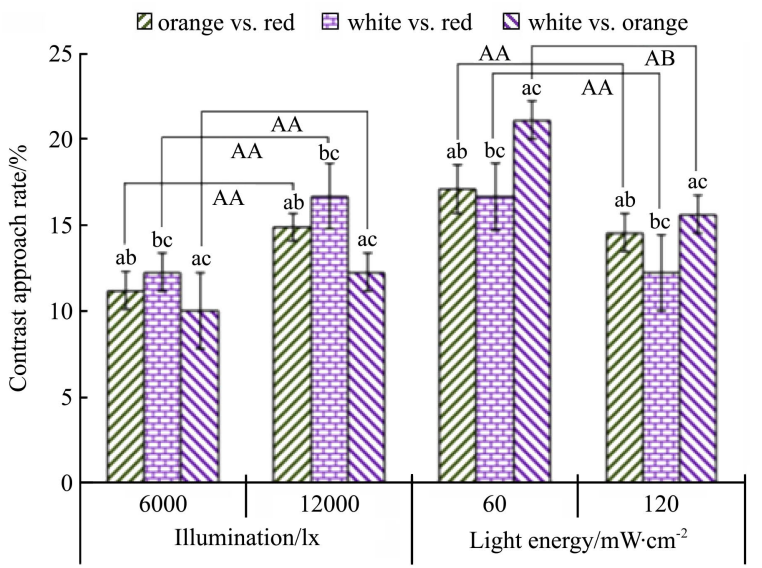

c. Contrast approach rate at $0-50 \mathrm{~mm}$

Note: The same small letter shows no significant difference $(p>0.025)$, different letters show significant differences $(p<0.025)$, different letters with $*$ or $\Delta$ show very significant differences $(p<0.025)$, and different letters with ${ }^{* *}, * *$, or $\Delta \Delta$ show extremely significant differences $(p<0.0001)$. Between 6000 and $12000 \mathrm{~lx}$, or 60 and $120 \mathrm{~mW} / \mathrm{cm}^{2}$, AA shows no significant difference $(p>0.025), \mathrm{AB}$, $\mathrm{A}^{*} \mathrm{~B}^{*}$, and, respectively, show significant differences $(p<0.025)$, very significant differences $(p<0.025)$, and $\mathrm{A}^{* *} \mathrm{~B}^{* *}$ show extremely significant differences $(p<$ $0.0001)$; the others show no significant differences $(p>0.025)$. The same as below.

Figure 3 Thrips total response degree and contrast selection effect for spectral light and contrast spectral light at $0-150 \mathrm{~mm}$
Furthermore, thrips approach sensitivity to white light was the best, followed by orange light, red light. While the contrast approach rate showed no significant difference among different pairings (df=2, $6000 \mathrm{~lx}: F=0.374, p=0.703 ; 12000 \mathrm{~lx}: F=2.561$, $p=0.157 ; 60 \mathrm{~mW} / \mathrm{cm}^{2}: F=2.702, p=0.146 ; 120 \mathrm{~mW} / \mathrm{cm}^{2}: F=1.18$, $p=0.37$ ) (Figure $3 \mathrm{c}$ ). The contrast approach rate in white vs. red light was the greatest (6000 lx: 12.21\%; 12000 lx: 16.65\%) under illumination, while when light energy stimulated thrips. The contrast approach rate in white vs. orange light was the greatest $\left(60 \mathrm{~mW} / \mathrm{cm}^{2}: 21.09 \% ; 120 \mathrm{~mW} / \mathrm{cm}^{2}: 15.54 \%\right)$. Illumination therefore made the thrips approach sensitivity to spectral light different from light energy. The worst total response rate, and the best contrast selective rate was white vs. red (6000 1x: 55.51\%; 12000 lx: 58.84\%), and orange vs. red light (6000 lx: 38.84\%; 12000 lx: $37.73 \%$ ), respectively, showing that red light drove thrips to select the sensitive spectral light, and was regulated by the enhanced light intensity.

3.2.2 The contrast selection effect of different pairings of yellow, green, violet, or UV light

There were significant differences of the total response sensitivity to different pairings $(\mathrm{df}=5,6000 \mathrm{~lx}: F=3.516, p=0.035$; $120001 \mathrm{x}: F=8.453, p=0.001 ; 60 \mathrm{~mW} / \mathrm{cm}^{2}: F=22.019, p<0.0001$; $120 \mathrm{~mW} / \mathrm{cm}^{2}: F=1.863, p=0.175$ ) (Figure $4 \mathrm{a}$ ). The total response degree for UV vs. violet light (6000 lx: $78.81 \%$; 12000 lx: 83.27\%) under illumination, and for UV vs. yellow light $\left(60 \mathrm{~mW} / \mathrm{cm}^{2}\right.$ : $82.15 \% ; 120 \mathrm{~mW} / \mathrm{cm}^{2}: 79.93 \%$ ) under light energy, were the best, respectively.

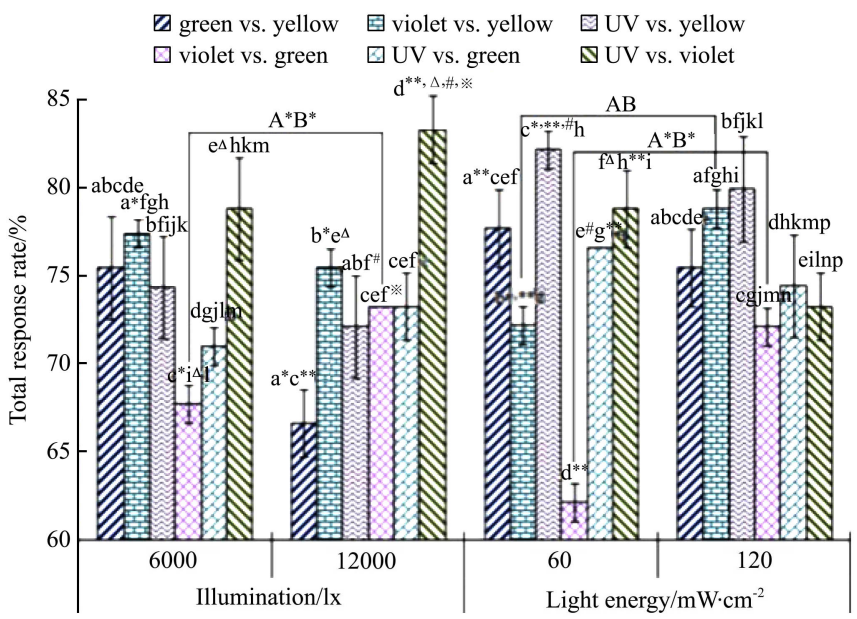

a. Total selective response rate at $0-150 \mathrm{~mm}$

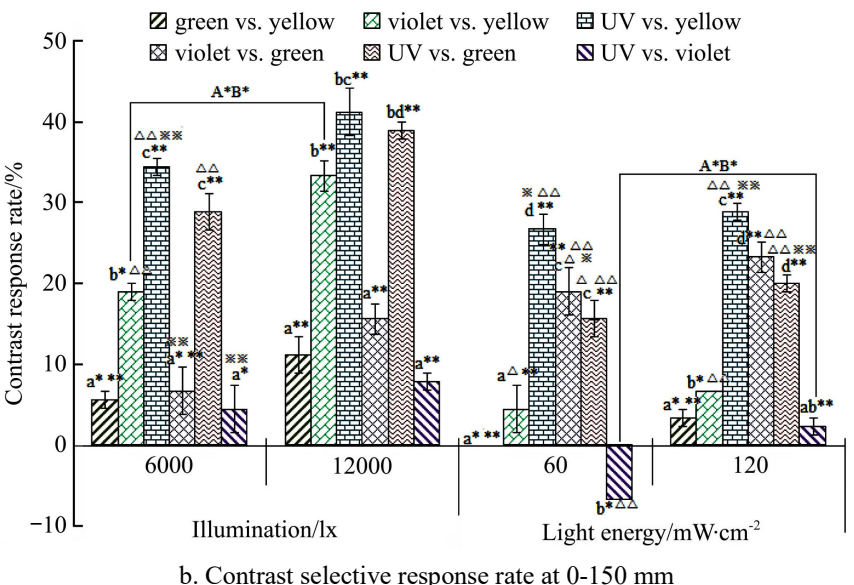

Figure 4 Total selective response rate and contrast selective response rate of western flower thrips adults for light spectra and contrast light spectra at $0-150 \mathrm{~mm}$ in two channels 
Moreover, between $6000 \mathrm{~lx}$ and $12000 \mathrm{~lx}$, at 60 and $120 \mathrm{~mW} / \mathrm{cm}^{2}$, respectively, there was a very significant sensitivity difference for violet vs. green light $(F=24.894, p=0.008 ; F=40.405, p=0.003)$, and a significant difference for violet vs. yellow light $(F=1.891$, $p=0.024 ; F=17.74, p=0.014)$. While $6000 \mathrm{~lx}$ showed that total response sensitivity to green vs. yellow $(75.49 \%)$, violet vs. yellow (77.36\%), and UV vs. yellow (74.37\%) light were better at $12000 \mathrm{~lx}, 120 \mathrm{~mW} / \mathrm{cm}^{2}$ for violet vs. yellow (78.81\%), and violet vs. green light $(72.16 \%)$ were better than at $60 \mathrm{~mW} / \mathrm{cm}^{2}$.

Under the same illumination conditions, the contrast response rates showed that the selective sensitivity to UV light was better. Under light energy, the selective sensitivity to $60 \mathrm{~mW} / \mathrm{cm}^{2}$ of violet light was better, while that to $120 \mathrm{~mW} / \mathrm{cm}^{2}$ of UV light was better.

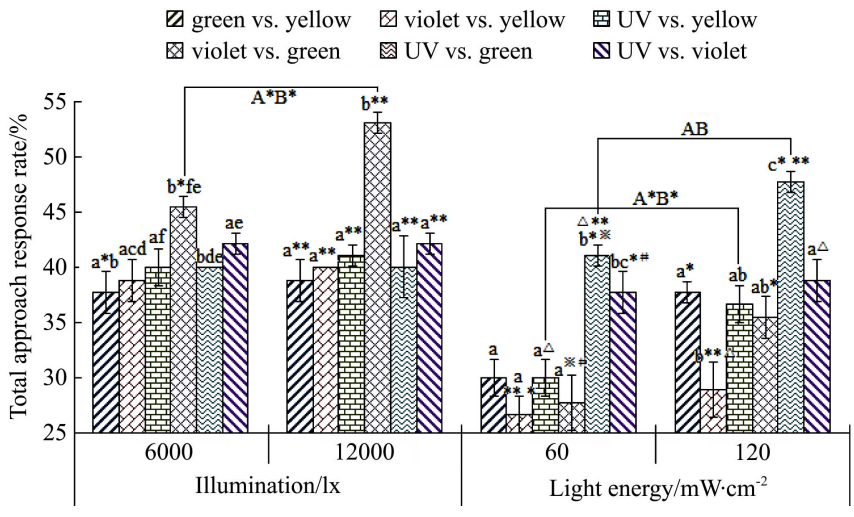

a. Total selective approaching response rate at $0-50 \mathrm{~mm}$
Moreover, there were extremely significant differences of the contrast selective sensitivity among different pairings under the same light condition $(\mathrm{df}=5, p<0.0001,6000 \mathrm{~lx}: F=53.78 ; 12000 \mathrm{~lx}$ : $F=58.30 ; 60 \mathrm{~mW} / \mathrm{cm}^{2}: F=38.72 ; 120 \mathrm{~mW} / \mathrm{cm}^{2}: F=89.04$ ) (Figure $4 \mathrm{~b})$. For the contrast response rate, UV vs. yellow light was the highest (6000 lx: 34.41\%; 12000 lx: 41.08\%; $60 \mathrm{~mW} / \mathrm{cm}^{2}$ : 26.63\%; $120 \mathrm{~mW} / \mathrm{cm}^{2}: 28.86 \%$ ), and the contrast response rate increased when light intensity increased (Figure $4 \mathrm{~b}$ ), indicating that thrips contrast selective response sensitivity was enhanced by the increasing intensity.

Thrips showed selectively different spectral light sensitivities, and the total approach rate and the contrast approach rate for different pairings differed from each other (Figures $5 \mathrm{a}$ and $5 \mathrm{~b}$ ).

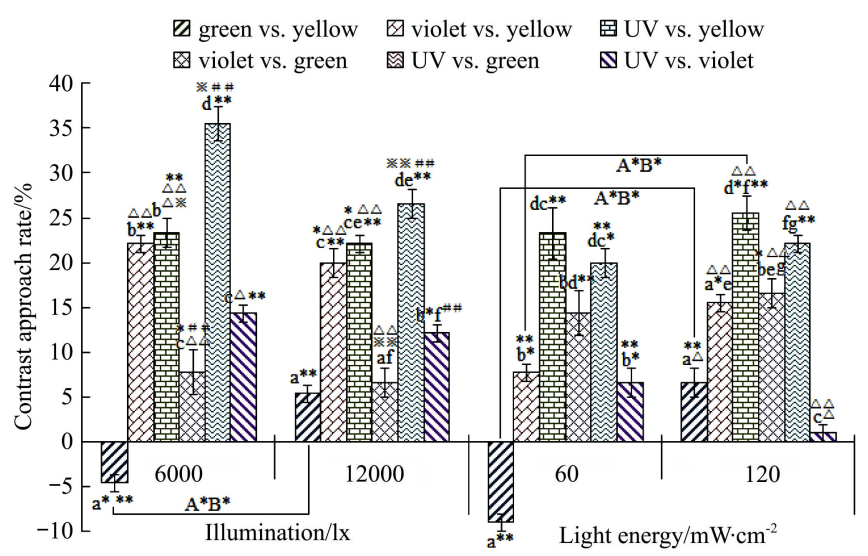

b. Contrast selective approaching response rate at $0-50 \mathrm{~mm}$

Figure 5 Total approach response rate and contrast approach response rate of western flower thrips adults for light spectra and contrast light spectra at $0-50 \mathrm{~mm}$ in two channels

Under the same light conditions, there were significant differences of the total approach rate among different pairings $(\mathrm{df}=56000 \mathrm{~lx}: F=2.894, p=0.061 ; 120001 \mathrm{~lx}: F=10.094, p=0.001$; $\left.60 \mathrm{~mW} / \mathrm{cm}^{2}: F=7.892, p=0.002 ; 120 \mathrm{~mW} / \mathrm{cm}^{2}: F=7.855, p=0.002\right)$ (Figure 5a). Under illumination, and light energy, respectively, the total approach rate for violet vs. green, and UV vs. green light were the best (6000 lx: $45.50 \%$; 12000 lx: $53.18 \% ; 60 \mathrm{~mW} / \mathrm{cm}^{2}$ : $41.07 \%$; $120 \mathrm{~mW} / \mathrm{cm}^{2}: 47.74 \%$ ); while green vs. yellow and violet vs. yellow light were the worst. When comparing $6000 \mathrm{~lx}$ with $12000 \mathrm{~lx}$, and comparing 60 with $120 \mathrm{~mW} / \mathrm{cm}^{2}$, respectively, the total approach sensitivity to $12000 \mathrm{~lx}$, and $120 \mathrm{~mW} / \mathrm{cm}^{2}$ was superior to $6000 \mathrm{~lx}$, and $60 \mathrm{~mW} / \mathrm{cm}^{2}$, respectively.

Moreover, there were significant differences of the contrast approach rates among different pairings $(\mathrm{df}=5, p<0.0001$ : $6000 \mathrm{~lx}$ : $F=55.078 ; 12000$ lx: $F=30.60 ; 60 \mathrm{~mW} / \mathrm{cm}^{2}: F=27.187 ; 120 \mathrm{~mW} / \mathrm{cm}^{2}$ : $F=28.785$ ) (Figure $5 b$ ). Under illumination and light energy, respectively, the contrast approach rate for UV vs. green (6000 lx: $35.54 \%$; $12000 \mathrm{~lx}: 26.63 \%)$, and UV vs. yellow $\left(60 \mathrm{~mW} / \mathrm{cm}^{2}\right.$ : $23.33 \% ; 120 \mathrm{~mW} / \mathrm{cm}^{2}: 25.54 \%$ ) light were the highest. The approach sensitivity to yellow light was superior to that of green light under $6000 \mathrm{~lx}$ and $60 \mathrm{~mW} / \mathrm{cm}^{2}$, while sensitivity to green light was superior to that of yellow light under $12000 \mathrm{~lx}$ and $120 \mathrm{~mW} / \mathrm{cm}^{2}$.
The approach sensitivity to UV light was the greatest, followed by violet light. There were significant differences for green vs. yellow light between $6000 \mathrm{~lx}$ vs. $12000 \mathrm{~lx}(F=30.188, p=0.005)$, 60 vs. $120 \mathrm{~mW} / \mathrm{cm}^{2}(F=72.573, p=0.001)$, and for violet vs. yellow light between 60 vs. $120 \mathrm{~mW} / \mathrm{cm}^{2} \quad(F=24.595, p=0.005)$. In summary, the stimulating effect of light illumination differed from light energy, and green light illumination and yellow light energy increased thrips approach sensitivity to select UV light, inhibiting with increasing illumination, and intensifying with increasing light energy, respectively.

\subsection{Discussion}

Previous studies have speculated that the photoreceptor types of thrips adults may include green, blue, and ultraviolet photoreceptors ${ }^{[17]}$, showing that these light spectra are recognized by insects, and can induce an optic nerve reaction, and may cause a phototactic response $\mathrm{e}^{[18,19]}$. In this study, we found that under $120 \mathrm{~lx}$, the spectral lights used in Experiment 1 all induced western flower thrips to show a selective visual response, and the response to blue light was the best, followed by UV, and green light (Table 3 ), indicating that only under the appropriate illumination, does the optic nerve sensitivity spectrum result in a better selective response.

Table 3 Selective response rate of western flower thrips adults induced by different spectral light at 0-150 mm/\%

\begin{tabular}{|c|c|c|c|c|c|c|c|c|}
\hline \multirow{2}{*}{$\begin{array}{c}\text { Illumination } \\
/ / \mathrm{x}\end{array}$} & \multicolumn{8}{|c|}{ Spectrum } \\
\hline & red & orange & yellow & green & blue & violet & U.V. & white \\
\hline 120 & $1.11 \pm 1.11 \mathrm{ab}^{* * *}$ & $2.22 \pm 1.11 \mathrm{aed}^{* *}$ & $4.44 \pm 1.11$ befg $^{* *}$ & $12.21 \pm 1.11 \mathrm{~h}^{\Delta * *}$ & $17.76 \pm 1.11 \mathrm{i}^{\triangle} \mathrm{i}^{* *} \Delta \Delta$ & $6.66 \pm 1.11 \mathrm{c}^{*} \mathrm{f}^{\Delta} \mathrm{j}^{\Delta \Delta}$ & $14.44 \pm 1.1 \mathrm{hi}^{* *} \Delta \Delta$ & $5.56 \pm 1.11 \mathrm{dg}^{\triangle} \mathrm{j}^{\Delta \Delta}$ \\
\hline
\end{tabular}

The labels are the same as shown in Table 2.

Previous studies has reported that tiny insects are more sensitive to green and yellow light ${ }^{[20]}$, and less sensitive to red and orange light ${ }^{[21]}$, and the attraction effects of UV light on many insects are better ${ }^{[22]}$. In our study, we found that under stronger photic conditions the stimulating effect of illumination or light 
energy made the selective sensitivity to UV, violet, and yellow light better, while red, orange, and white light sensitivity were worse (Table 1). Trichromophoric insects can use the opposing mechanism of color perception to select their favorite color light ${ }^{[23]}$, and spectrum and light intensity affect thrips phototactic selection $^{[24,25]}$. This may be a reason for the change of selective sensitivity to UV, violet, yellow, and green light under the same light conditions. The insect color and light perception provide a good visual guarantee for their behavior ${ }^{[26]}$, which may have caused the thrips visual response to generate the approach behavior. The difference of a mesopic stress state from dark vision to photopic vision stimulated by different spectral lights could have caused the different approach sensitivity (Table 2).

When illumination and light energy increased, the change of the selective sensitivity, and the approach sensitivity to the same light spectra were different (Tables 1 and 2). To reveal the functional effects of illumination and light energy, we measured the illumination and light energy of UV, violet, green, and yellow light at $50 \mathrm{~mm}$ and $150 \mathrm{~mm}$ (Table 4).

Table 1 and Table 4 show that under the same illumination, the stronger illumination at $150 \mathrm{~mm}$ induced a superior selective response degree (6000 lx: violet, 31.3 lx, 22.20\%; 12000 lx: yellow, $87.6 \mathrm{~lx}, 21.09 \%$ ). Under the same light energy, the stronger light energy at $150 \mathrm{~mm}$ caused the superior selective response degree $\left(60 \mathrm{~mW} / \mathrm{cm}^{2}\right.$ : violet, $0.10 \mathrm{~mW} / \mathrm{cm}^{2}, 25.46 \% ; 120 \mathrm{~mW} / \mathrm{cm}^{2}$ : violet, $\left.0.18 \mathrm{~mW} / \mathrm{cm}^{2}, 19.99 \%\right)$. These results indicated that thrips relied on the stronger visual stimulation information to respond to the sensitive light target as shown in Experiment 1 . When illumination increased from $6000 \mathrm{~lx}$ to $12000 \mathrm{~lx}$, at $50 \mathrm{~mm}$, light energy of violet and UV light was enhanced by $0.23 \mathrm{~mW} / \mathrm{cm}^{2}$ and $0.1 \mathrm{~mW} / \mathrm{cm}^{2}$, making the selective response degree increase by $7.52 \%$ and $4.02 \%$, respectively. When light energy increased from 60 to $120 \mathrm{~mW} / \mathrm{cm}^{2}$, illumination of violet, UV light was enhanced by 1868, and $1450 \mathrm{~lx}$, respectively, making the selective response degree decrease by $28.93 \%$, and $28.37 \%$, respectively (Table 2). Under illumination, spectral light quality therefore determined the approach sensitivity, intensified by light energy intensity when illumination increased, and under light energy, spectral light energy determined the approach sensitivity, and was inhibited by the intensity of illumination when light energy was increased.

Table 4 Measured illumination and light energy at 50 and $150 \mathrm{~mm}$

\begin{tabular}{|c|c|c|c|c|c|c|c|c|c|c|}
\hline & & \multirow{2}{*}{$\begin{array}{l}\text { Position } \\
/ \mathrm{mm}\end{array}$} & \multicolumn{4}{|c|}{ Illumination/lx } & \multicolumn{4}{|c|}{ Light energy $/ \mathrm{mW} \cdot \mathrm{cm}^{-2}$} \\
\hline & & & yellow & green & violet & UV & yellow & green & violet & UV \\
\hline \multirow{2}{*}{ Illumination/lx } & 6000 & 150 & 29.4 & 24.8 & 31.3 & 21.2 & 0.006 & 0.005 & 0.04 & 0.028 \\
\hline & 12000 & 150 & 87.6 & 62.5 & 39.6 & 36.5 & 0.023 & 0.019 & 0.042 & 0.054 \\
\hline \multirow{2}{*}{ Light energy $/ \mathrm{mW} \cdot \mathrm{cm}^{-2}$} & 60 & 150 & 322 & 289 & 134 & 123 & 0.09 & 0.058 & 0.10 & 0.06 \\
\hline & 120 & 150 & 522 & 458 & 342 & 262 & 0.16 & 0.11 & 0.18 & 0.17 \\
\hline \multirow{2}{*}{ Illumination/lx } & 6000 & 50 & 230 & 301 & 330 & 398 & 0.05 & 0.05 & 0.11 & 0.22 \\
\hline & 12000 & 50 & 660 & 1506 & 450 & 539 & 0.18 & 0.24 & 0.34 & 0.32 \\
\hline \multirow{2}{*}{ Light energy $/ \mathrm{mW} \cdot \mathrm{cm}^{-2}$} & 60 & 50 & 2700 & 2492 & 1332 & 1110 & 0.613 & 0.482 & 0.822 & 0.92 \\
\hline & 120 & 50 & 4860 & 4760 & 3200 & 2560 & 1.32 & 0.952 & 1.36 & 1.54 \\
\hline
\end{tabular}

In Experiment 2, under illumination, the stronger light energy was UV vs. violet light (Table 4), corresponding to the best total response degree (Figure 4a), intensifying by $4.46 \%$ when illumination increased from $6000 \mathrm{~lx}$ to $12000 \mathrm{~lx}$, and thus indicating that light energy intensity of illumination decided the selective sensitivity. Under light energy, the total response degree for UV vs. yellow light was the best, corresponding to the maximum difference of illumination (UV vs. yellow), and indicating that illumination of spectral light energy affected the selective sensitivity, by a $2.22 \%$ decrease when light energy increased from $60 \mathrm{~mW} / \mathrm{cm}^{2}$ to $120 \mathrm{~mW} / \mathrm{cm}^{2}$. The contrast selective sensitivity to UV vs. yellow light was the greatest, and UV vs. violet light was the worst (Figure $4 b$ ), originating from the difference of visual sensitivity, regulated by the intensity of light. Thus, spectral light illumination and energy changed thrips visual selection response, affecting the approach behavior. These may originate from the difference of thrips bio-sensitivity to different photoelectric conversion intensity of LED spectral light illumination and energy, causing photo-thermal effects of LED photoelectric output, and finally affecting the thrips sensitivity selection response.

A study has reported that many tiny insects, such as thrips, whitefly, and aphids, can sensitively perceive blue and yellow color in background light, and when daylight illumination was $4000 \mathrm{~lx}$, the attraction effect was the best ${ }^{[27]}$. While not all spectral light backgrounds induced the selective responses of the thrips, as shown in Table 1 and Figure 3, thrips selective sensitivity to red light was the worst, causing the selection of other spectral light types, similar to the results reported in Mika et al. ${ }^{[28]}$. Some studies have also found that photoreceptors in compound eyes of thrips and whiteflies are very sensitive to the UV spectrum $(200-400 \mathrm{~nm})^{[29]}$, and our results showed that the selective sensitivity to $365 \mathrm{~nm}$ light was the best, followed by violet, and yellow light (Figures 4 and 5 ); and yellow and green light intensity regulated the approach sensitivity to select UV light. These results could indicate synergetic effects of photo pigments, screening pigments, and sensitizing pigments in insect compound eyes ${ }^{[30-33]}$.

\section{Conclusions}

The present study showed that the sensitive selection response effect of western flower thrips to spectral light changed by enhancing the illumination and energy, presenting an intensifying or inhibiting effect to alter their approach sensitivity. The stimulating effect of UV vs. violet light energy, and the co-regulatory effects of UV vs. violet light caused a better response sensitivity under the same illumination conditions, and light energy, respectively. Moreover, yellow and green light enhanced the approach sensitivity to UV and violet light and red light drove thrips to select other light spectra. These results indicated that the driving effect of red light enhanced thrips visual selection response effect for UV and violet light coupled with yellow or green light. However, our results are still insufficient to explain the influencing effect of different light spectral characteristics on the selective approach behavior, such as the photo-thermal effects of light on the 
insect approach sensitivity. Further experiments are required to obtain a physiological understanding of insect visual responses to light spectra.

\section{Acknowledgements}

We acknowledge financial support from the Research and Development of New Anti-Moth Materials for Sub Projects of National Key R\&D Projects and Evaluation of Control Effects (Grant No.2017YFD0200907), the China Agricultural Research System (Grant No.CARS-03). And Research and Application of New Trapping Technology for Thrips (Grant No.2019CY05).

\section{[References]}

[1] Schneweis D J, Whitfield A E, Rotenberg D. Thrips developmental stage-specific transcriptome response to tomato spotted wilt virus during the virus infection cycle in Frankliniella occidentalis, the primary vector. Virology, 2017; 500: 226-237.

[2] Gao Y L, Lei Z R, Reitz S R. Western flower thrips resistance to insecticides: detection, mechanisms and management strategies. Pest Manag Sci, 2012; 68(8): 1111-1121.

[3] Abdul M D, Song J H, Seo H J, Choi J J. Monitoring thrips species with yellow sticky traps in astringent persimmon orchards in Korea. Applied Entomology and Zoology, 2018; 53: 75-84.

[4] Liu Q H, Zhou Q. Physiological response of locusts to eye stimulation by spectral illumination for phototactic pest control. Int J Agric \& Biol Eng, 2016; 9(2): 186-194.

[5] Abdullah Z S, Greenfield B P, Ficken K J, Taylor J W, Wood M, Butt T M. A new attractant for monitoring western flower thrips, Frankliniella occidentalis in protected crops. Springer Plus, 2015; 4(1): 1-9.

[6] Vernon R S, Gillespie D R. Influence of trap shape, size, and background color on captures of Frankliniella occidentalls (Thysanoptera: Thripidae) in a cucumber greenhouse. J Econ Entomol, 1995; 88: 288-293.

[7] Wu Q J, Xu B Y, Zhang Y J, Zhang Z J, Zhu G R. Taxis of western flower thrips to different colors and field efficacy of the blue sticky cards. Plant Protection, 2007; 33(4): 103-105.

[8] Haga H, Katai Y, Mannen J, Masui S. Attraction of melon trips, Trips palmi(Karny), to color sheets and LED lights. Jpn. J. Appl. Entomol. Zool., 2014; 58: 17-22.

[9] Matteson N, Terry I, Ascoli CA, Gilbert C. Spectral efficiency of the western flower thrips, Frankliniella occidentalis. Journal of Insect Physiology, 1992; 38(6): 453-459.

[10] Liu Q H, Zhou Q. Comparative investigation of locust's phototactic visual spectrum effect and phototactic response to spectral illumination. Spectrosc. Spectral Anal., 2014; 34: 1593-1596.

[11] Otani Y, Wakakuwa M, Arikawa K. Relationship between Action Spectrum and Spectral Sensitivity of Compound Eyes Relating Phototactic Behavior of the Western Flower Trips, Frankliniella occidentalis. Jpn. J. Appl. Entomol. Zool, 2014; 58: 177-185.

[12] Liu Q H, Jiang Y L, Zhou Q. Spectral vision acuity reaction detection of phototactic response of Locusta migratoria to LED light signal. Trans. Chin. Soc. agric. Machine., 2016; 28(8): 338-344.

[13] Kishi M, Wakakuwa M, Kansako M, Inuma T, Arikawa K. Action spectrum of phototactic behavior and compound eye spectral sensitivity in the yellow tea trips, Scirtothrips dorsalis Hood (Tysanoptera: Tripidae) . Jpn. J. Appl. Entomol. Zool, 2014; 58: 13-16.

[14] Liu Q H, Jiang Y L, Miao J, Gong Z G, Li T, Duan Y, Wu Y Q.
Regulation of visual sensitivity responses in locusts stimulated by different spectral lights. Pakistan J. Zool., 2019; 51(6): 2245-2255.

[15] Liu Q H, Zhou Q. Comparative investigation of locusts visual bio-selection response effect induced by incentive effect of polarized light and spectral light. Chin. Soc. agric. Machine., 2018; 49(6): 238-406.

[16] Fan F, Ren H M, Lu L H, Zhang L P, Wei GS. Effect of spectral sensitivity and intensity response on the phototaxis of Frankliniella Occidentalis (Pergande). Acta Ecologica Sinica, 2012; 32(6): 1790-1795.

[17] Murata M, Hariyama T, Yamahama Y, Toyama M, Ohta I. Effects of the range of light wavelengths on the phototactic behavior and biological traits in the melon thrips, Thrips palmi Karny (Thysanoptera: Thripidae). Ethol Ecol Evol. 2017; 59: 93-95.

[18] Saunders D. Insect photoperiodism: seeing the light. Physiol Entomol, 2012; 37: 207-218.

[19] Quan Y, Yang X, Yan Z Q, Han C, Lily Y J, Jan Y N. Light-induced structural and functional plasticity in Drosophila larval visual system. Science, 2011; 333(6048): 1458-1462.

[20] Liu Q H, Xin Z, Zhou Q. Visual reaction effects induced and stimulated by different lights on phototactic bio-behaviors in Locusta migratoria manilensis. Int J Agric \& Biol Eng, 2017; 10(4): 173-181.

[21] Masami S, Kenichiro H. Insect reactions to light and its applications to pest management. Appl Entomol Zool, 2013; 48: 413-421.

[22] Ji Y Y, Bo-Kyung S, Lee H S. Phototactic behavior 8: phototactic behavioral responses of western flower thrips, Frankliniella occidentalis Pergande (Thysanoptera: Thripidae), to light-emitting diodes. J Korean Soc Appl Biol Chem, 2015; 24(2): 15-20.

[23] Cowan T, Gries G. Ultraviolet and violet light: attractive orientation cues for the Indian meal moth, Plodia interpunctella. Entomol Exp Appl., 2009; $131: 148-158$

[24] Koshitaka H, Kinoshita M, Vorobyev M, Arikawa K. Tetrachromacy in a butterfly that has eight varieties of spectral receptors. Proc R Soc Lond B, 2008; 275: 947-954

[25] Cao Y, Zhi J R, Li C, Zhang R Z, Wang C, Shang B Z, Gao Y L. Behavioral responses of Frankliniella occidentalis to floral volatiles combined with different background visual cues. Arthropod Plant Interactions, 2018; 12: 31-39.

[26] Liu Q H, Zhou Q. Influence of locusts visual reaction effect stimulated by orange light on response effect. J. Biobased Mater. Bioenergy., 2017; 11: 274-280.

[27] Zhang A S, Yu Y, Zhuang Q Y, Song Y Q, Peng Z Y, Zhou X H, et al Effect of spectral sensitivity and intensity on the behavioral response of the Thrips palmi female adult. Acta Ecologica Sinica, 2015; 35(11): 3555-3561.

[28] Xiao C K, Zheng J Q, Shi Y C, Hu T J, Li W M. The preference of western flower thrips to different colours of sticky cards and their insect attracting effect. Plant Quarantine, 2008; 21(3): 155-157.

[29] Mika M, Takahiko H, Yumi Y, Mina T, Izumi O. In the presence of red light, cucumber and possibly other host plants lose their attractability to the melon thrips Thrips palmi (Thysanoptera: Thripidae). Applied Entomology and Zoology, 2018; 53: 117-128.

[30] Pan H S, Xiu C, Lu Y H. A combination of olfactory and visual cues enhance the behavioral responses of Apolygus lucorum. J Insect Behav, 2015; 28(5): 525-534.

[31] Gong Z, Liu J, Guo C, Zhou Y Q, Teng Y, Liu L. Two pairs of neurons in the central brain control Drosophila innate light preference. Science, 2010; 330(3): 499-502.

[32] Hori M, Shibuya K, Sato M, Saito Y. Lethal effects of short wavelength visible light on insects. Sci Rep, 2014; 4: 73-83.

[33] Thomas A M, Rava A S, Sandra S. Approach sensitivity in the retina processed by a multifunctional neural circuit. Nature, 2009; 10: 201-211. 